\title{
Estimation of fusaric acid from culture filtrate of Fusarium udum by thin layer chromatography
}

\section{S.B. SHINDE AND H.V. DESHMUKH}

Department of Plant Pathology and Agricultural Microbiology, Mahatama Phule Krishi Vidyapeeth, Rahuri, AHMEDNAGAR (M.S.) INDIA

Email : shindesb123@gmail.com

The investigation was undertaken to estimate fusaric acid from culture filtrate of Fusarium udum by using thin layer chromatography. Acidic $\mathrm{pH}$ (3.00), temperature 28 to $30^{\circ} \mathrm{C}$ and 20 days after incubation was found to be optimum for maximum fusaric acid production.

Key words : Thin layer chromatography, Fusarium udum, Fusaric acid

How to cite this paper : Shinde, S.B. and Deshmukh, H.V. (2014). Estimation of fusaric acid from culture filtrate of Fusarium udum by thin layer chromatography. Asian J. Bio. Sci., 9 (2) : 251-254. 